\title{
Application of the D-type method of analysis for determining the longitudinal moments in bridge decks
}

Proc. Instn Civ. Engrs Structs \& Bldgs, 1993, 99, May, 239-240

Paper 9800

\author{
M. J. Ryall
}

L. Wadsworth, Consultant, Worcester The $D$-type method provides a rapid method of determining the longitudinal moments in a deck but whether assessing an existing bridge or designing a new structure, a designer needs more information than this. The designer also needs a value for the transverse moment, and information about the distribution of reactions and slopes at the bearings is useful.

65. Over 25 years ago, I had a need to analyse the effects of the $\mathrm{HB}$ vehicle on a composite steel beam deck where the transverse distribution was through the concrete slab only. I found the existing methods unattractive so I developed a procedure for the analysis of right bridge decks by finite differences. The original program ran on an ICL 1902 computer but, over the years, the increasing power of desktop machines has allowed versions to be mounted on personal computers, with only 512 $\mathrm{kb}$ of RAM. The program has been calibrated and approved by the HECB.

66. The requirement was for a fast and effi. cient method of analysis for right bridge decks. The original program therefore made the assumption that two opposite sides would be simply supported and the other two sides would be free. Using a regular rectangular mesh drawn on the deck, the finite difference formulation of equation (1) was encoded, the appropriate boundary conditions being allowed for at the four edges. Thus the differing bending and torsional stiffnesses of pseudoslabs are catered for, and the ability to add a stiffening beam to any grid line facilitates the application of the method to composite decks or to the analysis of decks with edge beams.

67. My interests now lie mainly in building structures rather than bridges. The program has been developed over the years so that the current version allows any combination of free or symmetric edges and either rigid or flexible supports to be specified at any node of the mesh. Loads are specified as whole or part UDLs, line loads between specified nodes or the HB vehicle (number of units and $X$ and $Y$ offset from node 1 to the leading wheel). When the HB vehicle is present, an internal routine distributes the wheel loads automatically to the adjacent nodes. The output is in the form of a list of the nodes, against each of which is listed the load at that node, the deflection, $M_{\mathrm{x}}, M_{\mathrm{y}}, M_{\mathrm{x} y}$, and the reactions at supported nodes. Wood-
Armer moments for reinforcement design are also calculated and enveloped if there are multiple load cases.

68. Therefore, a general method exists for the analysis of rectangular beam-slab bending problems which entails the minimum of data preparation. Finite differences have to give way to finite elements when the planform is nonrectangular but, for rectangular slabs or bridge decks, there are large differences in the solution time and storage requirements for the two methods. For example, with finite elements a $20 \times 20$ grid will produce 1200 equations, a half-band width of 66 , and 79200 elements to be stored. With finite differences, the numbers are 400 equations, a half-band width of 41 , and only 16400 elements. This method deserves consideration alongside the other well-known methods mentioned in the Paper.

69. Although it is of no consequence with regard to the validation of the $D$-type method, there is an error in the modelling of example 4 in the Paper. The bending inertia of one com. posite beam has been divided by the beam spacing to obtain the distributed inertia, but the width of the deck has been taken as the actual width not four times the beam spacing. This introduces two inaccuracies: firstly, the total longitudinal strength and stiffness are higher in the model than in reality; secondly, the edge distance is distorted in the model because the extra strength is provided outside the load position. When the deck is modelled correctly, the moment in the worst beam is found to be $1852 \mathrm{kNm}, 13.3 \%$ greater than the moment given in the Paper.

70. Figure 16 shows the preparation of the data needed to analyse example 4 as a beamstiffened slab. The data for a pseudo-slab model are similar, except that the distributed inertias instead of the solid slab and beam details are input.

71. I carried out two runs of the finite difference program in order to analyse example 4 of the Paper: firstly, as a pseudo-slab but with a width of $11200 \mathrm{~mm}$ (i.e. four times the beam spacing); secondly, as a $220 \mathrm{~mm}$ deep solid slab stiffened by four beams of inertia $1.52 \times 10 \mathrm{~mm}^{4}$ in the correct positions. The first run gives a result of $2.8 \times\left(M_{y}\right.$ at node 38$)=$ $2.8 \times 669.26=1874 \mathrm{kNm}$; the second run gives a value of the beam moment directly as 1852 $\mathrm{kNm}$. Each run took less than 15 minutes from
Paper published: Proc. Instn Civ. Engrs Structs \& Bldgs, 1992, 94, May, $157-169$ 
Fig. 16. Example 4: model for 'slab' turning on the computer to printing the results, including diagrams of distributions of moment and deflection (the printouts are available).
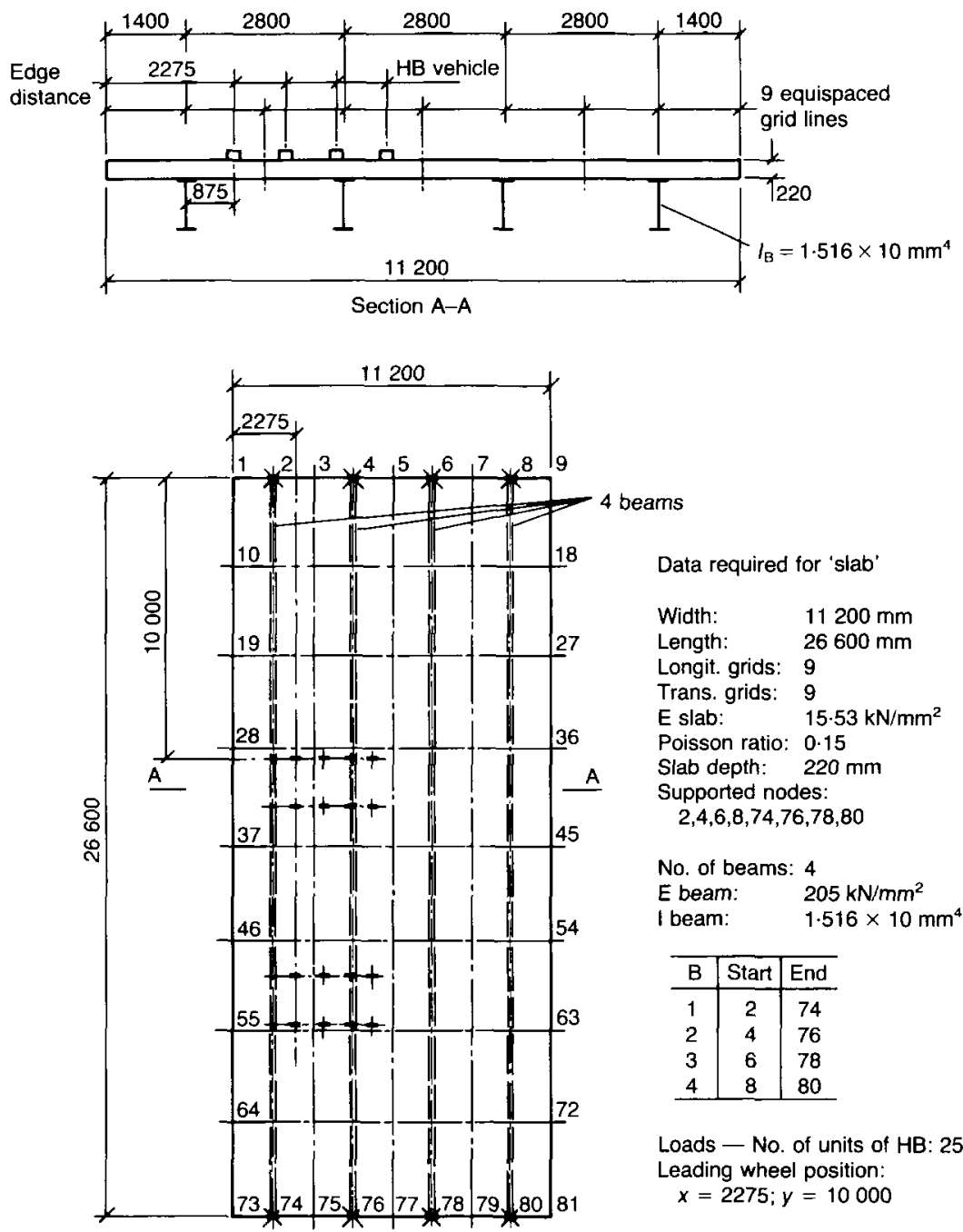

Data required for 'slab'

Width: $\quad 11200 \mathrm{~mm}$ Length: $\quad 26600 \mathrm{~mm}$

Longit. grids: 9

Trans. grids: 9

E slab: $\quad 15.53$

Poisson ratio: 0.15

Slab depth: $220 \mathrm{~mm}$

Supported nodes:

$2,4,6,8,74,76,78,80$

No. of beams: 4

E beam: $\quad 205 \mathrm{kN} / \mathrm{mm}^{2}$

I beam: $\quad 1.516 \times 10 \mathrm{~mm}^{4}$

\begin{tabular}{c|c|c}
\hline $\mathrm{B}$ & Start & End \\
\hline 1 & 2 & 74 \\
2 & 4 & 76 \\
3 & 6 & 78 \\
4 & 8 & 80 \\
\hline
\end{tabular}

Loads - No. of units of $\mathrm{HB}: 25$ Leading wheel position $x=2275 ; y=10000$

72. The generalized finite difference program can be used to study beam-slab composite action in buildings, foundations with Winkler supports and retaining walls, as well as bridge decks.

\section{Mr Ryall,}

The $D$-type method has now been developed further and, in fact, we now have a facility for calculating all of the deflections and stress resultants throughout the deck area vehicle for any position of the HB and HA loading combined. Even so, the longitudinal movement is usually of first interest to a designer and/or an assessing engineer, and enables sound decisions to be made for further more detailed analysis. Clearly, if a deck fails at this point, then decisions about rehabilitation, upgrading or weight restrictions have to be made when assessing; and if designing, then a good first shot at the transverse cross-section can be made with this information.

74. I was very interested in the finite difference approach, and the program developed has clear advantages over finite element or grillage techniques for simple planforms. The $D$-type programme we have developed can now accomplish similar feats, and is being developed further to cater for skew and for continuous bridges.

75. The error in the modelling of example 4 has been noted. I was interested in the times taken to run example 4. After I had rerun it on the updated program, the total time taken was less than two minutes; indeed, to find a single $D$ value takes a few seconds.

76. The main purpose of the Paper was to aim at developing a simple graphical method of finding the maximum stress resultant; this aim, I feel, has been achieved. 